\title{
A steroidogenic cell line with differentiation potential from mouse granulosa cells, transfected with Ad4BP and SV40 large T antigen genes
}

\author{
Y Kamei, Y Aoyama ${ }^{1}$, T Fujimoto, N Kenmotsu ${ }^{1}$, C Kishi ${ }^{2}$, \\ M Koushi, S Sugano ${ }^{3}$, K Morohashi ${ }^{4}$, R Kamiyama and R Asakai ${ }^{1}$ \\ Graduate School of Allied Health Sciences, Tokyo Medical and Dental University, 1-5-45 Yushima Bunkyouku, Tokyo, Japan \\ ${ }^{1}$ Department of Endocrinology, Medical Research Institute, Tokyo Medical and Dental University, 1-5-45 Yushima Bunkyouku, Tokyo, Japan \\ ${ }^{2}$ Graduate School of Medicine, Tokyo Medical and Dental University, 1-5-45 Yushima Bunkyouku, Tokyo, Japan \\ ${ }^{3}$ Laboratory of Functional Genomics, Department of Medical Genome Science, Graduate School of Frontier Sciences, The University of Tokyo, \\ 4-6-1 Shirokanedai, Minatoku, Tokyo, Japan \\ ${ }^{4}$ Division for Sex Differentiation, National Institute for Basic Biology, National Institutes of Natural Sciences, Higashiyama 5-1, Myondaiji-cho, Okazaki, Japan \\ (Requests for offprints should be addressed to R Asakai; Email: asakai@jiu.ac.jp) \\ (R Asakai, Y Aoyama and Y Kamei are now at Josai International University, Faculty of Pharmaceutical Sciences, Department of Morphophysiology, \\ 1 Gumyo Togane, Chiba 283-8555, Japan)
}

\begin{abstract}
Several steroidogenic cell lines of granulosa cells (GC) have been used to elucidate differentiation mechanisms of GC during folliculogenesis. These cell lines, however, are of limited usefulness since they have lost some of their differentiation potential. The transcription factor adrenal-4 binding protein (Ad4BP), also known as steroidogenic factor-1 or NR5A1, is essential for the expression of all P-450 steroidogenic enzymes. By transfection with the Ad4BP gene together with SV40 DNA, we have generated several steroidogenic cell lines. One selective clone, named 4B2, retained its steroidogenic potential and was therefore analyzed in depth. This cell line responded to 8-Br-cAMP by displaying differentiation characteristics similar to those occurring in the differentiation process of primary cultured GC, including enhanced progesterone
\end{abstract}

secretion, a cell shape change from a fibroblastic to epithelioid conformation, elongated mitochondria, increased gap junction formation and inhibition of cell proliferation. Prostaglandin $\mathrm{E}_{2}\left(\mathrm{PGE}_{2}\right)$, an intraovarian regulator of GC, stimulated cAMP production, and this eicosanoid, like 8-Br-cAMP, induced differentiation properties with the exception of cell conformation in 4B2 cells. These results suggest that expression of Ad4BP may provide the basis for a repertoire of cAMP-sensitive differentiation properties, including morphological alterations and growth inhibition. Thus, the 4B2 cell line may serve as a tool for elucidation of differentiation mechanisms that are under the control of Ad4BP.

Journal of Endocrinology (2005) 185, 187-195

\section{Introduction}

Granulosa cells (GC) are committed to differentiation under the control of follicle-stimulating hormone (FSH) and luteinizing hormone (LH), which transmit signals mainly through cAMP signaling. The stimulated GC can synthesize a large amount of sex steroids through development of P-450 steroidogenic enzymes, and they also undergo changes in cellular structure of mitochondria and gap junctions while ceasing cell growth (Hsueh et al. 1984). Although much is known about the molecular and cellular processes of differentiation in GC, the precise mechanisms still remain to be elucidated. Differentiation of GC has been studied mostly in primary cultured GC. Drawbacks to this system include limitations in the number of available cells and in the time that cells can retain their differentiation potential. Moreover, primary cultured GC lack monoclonality, because they are isolated from ovaries that contain follicles of various sizes and that are undergoing different developmental processes. Thus, it would be desirable to establish an immortalized GC line. However, immortalization usually results from the constitutive expression of oncogene(s), including SV40 DNA, and as a result most of the differentiation properties of the cells are lost (Amsterdam et al. 1988). This problem can be alleviated, in part, by cotransfection with other genes, such as Ha-ras (Sun \& Amsterdam 1990) and p53 (Hosokawa et al. 1998). The complete recovery, however, of the differentiation properties that were lost in the GC lines appears to be extremely difficult. 
One member of the orphan nuclear receptor subfamily, the adrenal-4 binding protein (Ad4BP), also known as steroidogenic factor-1 or NR5A1, regulates the transcription of essentially all P-450 steroidogenic enzymes, including enzymes involved in the synthesis of sex steroids in the ovary (Lala et al. 1992, Morohashi et al. 1993, Nuclear Receptor Nomenclature Committee 1999). Since mice null for Ad4BP are born without gonadal and adrenal development, they do not provide further information about the role of Ad4BP in the development of the ovarian follicle during the estrous cycle (Zhao et al. 2001). It has been reported that steroidogenic GC lines express Ad4BP, whereas GC lines lacking steroidogenesis completely lose the expression of this transcription factor (Keren-Tal et al. 1997). These data account only for the role of Ad4BP in steroidogenesis and organogenesis, but it still remains unclear whether Ad4BP is essential to develop a whole repertoire of differentiation properties.

In this work, we attempted to establish a new cell line that retains its differentiation potential by transfecting genes for Ad4BP, together with SV40 large T antigen, into primary cultured mouse GC. After selection of several clones synthesizing high levels of progesterone (PRG), we studied one clone, named 4B2, extensively in the context of GC differentiation. The differentiation consequences of activation of cAMP signaling pathways were examined, including morphological alterations and proliferative activity. The results revealed that cAMP signaling activators induced steroidogenesis and morphological changes and inhibited growth activity in 4B2 cells, as described similarly in the differentiation processes of primary cultured GC (Hsueh et al. 1984). These data suggest that the 4B2 cell line may be useful to study the differentiation properties of GC that are associated with the expression of Ad4BP.

\section{Materials and Methods}

\section{Reagents}

LipofectAMINE reagent was purchased form Gibco BRL (Paisley, UK). Prostaglandin $\mathrm{E}_{2}\left(\mathrm{PGE}_{2}\right)$ was purchased from Cayman Chemical Company (Ann Arbor, MI, USA). $\mathrm{N}$-[2-(p-Bromocinnamylamino)ethyl]-5-isoquinoline sulphonamide dihydrochloride (H89), 8-Br-cAMP, forskolin, cycloheximide, cholera toxin, 1,3-dimethylxanthine, protein kinase A (PKA), cAMP and goat immunoglobulin G $(\mathrm{IgG})$ were purchased from Sigma. Actinomycin D and BSA were purchased from Seikagaku Corporation (Tokyo, Japan). A PRG assay kit was from Diagnostic Products (Los Angeles, CA, USA). A monoclonal SV40 large T antigen antibody and anti-inhibin alpha subunit polyclonal antibody were from Santa Cruz Biochemistry (Santa Cruz, CA, USA). The Vectastain Elite ABC kit was from Vector Laboratories (Burlingame, CA, USA). $\left[{ }^{3} \mathrm{H}\right] \mathrm{cAMP}$ (20-30 Ci/mmol) was from Amersham Biosciences
(Buckinghamshire, UK). Lucifer yellow, MitoTracker Red and FITC-labeled secondary antibodies were purchased from Molecular Probes (Eugene, OR, USA). Pregnant mare's serum gonadotropin was purchased from Teikoku Hormone Manufacturing Company (Tokyo, Japan). Ovine FSH and LH were obtained from the National Hormone and Pituitary Program (Baltimore, MD, USA).

\section{Transfection of mouse GC and establishment of cell lines}

GC were isolated from 24-day-old C57BL/6N immature female mice, $48 \mathrm{~h}$ after injection of $10 \mathrm{IU}$ pregnant mare's serum gonadotropin. (Animal experiment procedures were conducted in compliance with Guideline for Animal Experimentation at Tokyo Medical and Dental University.) Cells were cultured in a basic medium comprised of DMEM, $10 \mathrm{mM}$ HEPES-NaOH (pH 7.5) and $100 \mathrm{IU} / \mathrm{ml}$ penicillin, supplemented with $10 \%$ fetal bovine serum (FBS) (Asakai et al. 1995). Primary cultures on $3.5 \mathrm{~cm}$ plates were transfected with $2 \mu \mathrm{g}$ plasmid containing SV40 large $\mathrm{T}$ antigen ( $\mathrm{pEF} 321-\mathrm{T}$ ) either alone (Kim et al. 1990) or in combination with $3 \mu \mathrm{g}$ plasmid RSV/Ad4BP (Morohashi et al. 1993) encoding full-length Ad4BP cDNA, using the LipofectAMINE reagent. In the presence of neomycin, densely growing foci of transformed cells emerged within 2 weeks, and 96 foci were selected and transferred to culture plates. After 3 days, growing cells were further expanded to $10 \mathrm{~cm}$ plates, and the cells were collected and stored in liquid nitrogen. Clones were screened and selected by their ability to secrete high amounts of PRG into the culture medium. Cells were maintained in a basic medium containing 10\% FBS. Further studies were conducted with basic medium unless otherwise noted. When dimethyl sulfoxide (DMSO) was used as a vehicle for reagents, DMSO (below 0.2\%) alone was utilized as a negative control, and it showed no significant effects on the assay variables studied here.

\section{Measurement of PRG and $C A M P$}

For the determination of PRG production, cells were incubated with or without the indicated reagents in basic medium containing $10 \%$ FBS for various time periods, and the culture medium was then used directly for radioimmunoassay (RIA). Both extracellular and intracellular cAMP levels were determined as described (Gilman 1970). Cells in $3.5 \mathrm{~cm}$ plates were cultured in basic medium containing $0 \cdot 2 \%$ FBS overnight and then were stimulated with $\mathrm{PGE}_{2}(100 \mathrm{ng} / \mathrm{ml})$ for $4 \mathrm{~h}$ in the presence of $1 \mathrm{mM}$ 1,3-dimethylxanthine, a cyclic nucleotide phosphodiesterase inhibitor. After collecting culture medium for measurement of extracellular cAMP, cells were treated with $5 \%$ trichloroacetic acid and boiled for $5 \mathrm{~min}$, for determination of the intracellular cAMP. The values for inter- and intra-assay coefficients for RIA were below $10 \%$. 


\section{Immunocytochemistry}

For the detection of Ad4BP or SV40 large T antigen, cells were fixed with acetone/ethanol (1:1) for $15 \mathrm{~min}$ at $-20{ }^{\circ} \mathrm{C}$, and then dried and stored at $-20{ }^{\circ} \mathrm{C}$. After blocking with 3\% BSA in PBS, cells were rinsed and incubated for $1 \mathrm{~h}$ with a polyclonal Ad4BP antibody (1:100) (Morohashi et al. 1993) or with a monoclonal SV40 large $\mathrm{T}$ antigen antibody (1:100) (Kim et al. 1990) in 3\% BSA in PBS. After washing with 1\% Tween-20 in PBS, cells were incubated for $1 \mathrm{~h}$ with a FITC-labeled secondary antibody (1:100) in 3\% BSA in PBS and washed. Fluorescence was visualized with confocal microscopy, using a Leica TCS NT excited by the $488 \mathrm{~nm}$ line of an argon-krypton laser, and detected through a $510-530 \mathrm{~nm}$ bandpass emission filter.

For inhibin immunocytochemistry, cells were fixed with $10 \%$ formalin in PBS for $30 \mathrm{~min}$ and permeabilized with $0 \cdot 03 \%$ Triton $\mathrm{X}-100$ for $5 \mathrm{~min}$ at room temperature. Then, cells were treated with $0 \cdot 3 \%$ hydrogen peroxide in methanol to quench endogenous peroxidase activity. Nonspecific binding of antibody was blocked with 3\% BSA in PBS overnight. After incubation with goat antiinhibin alpha subunit polyclonal antibody (sc-22048, $1: 100)$ or goat IgG in PBS containing 3\% BSA overnight at $4{ }^{\circ} \mathrm{C}$, cells were stained with the Vectastain Elite ABC kit according to the manufacturer's instructions. Porcine GC, prepared as described previously (Asakai et al. 1995), were used as a positive control (data not shown).

\section{Detection of gap junctions and staining of mitochondria}

After 48-h incubation with or without $0.3 \mathrm{mM}$ cAMP or $1 \mu \mathrm{g} / \mathrm{ml} \mathrm{PGE}{ }_{2}$, mitochondria were stained in the presence of each reagent by incubating cells for $30 \mathrm{~min}$ in a basic medium containing 500 nM MitoTracker Red. Detection of gap junctions was achieved by the scrape-loading technique with Lucifer yellow (Luo et al. 1997). After incubation with each reagent for $24 \mathrm{~h}$, cells were scraped with a blade and incubated with $0 \cdot 02 \%$ Lucifer yellow for $10 \mathrm{~min}$ and then washed with PBS. Fluorescent images were acquired by confocal microscopy. MitoTracker Red was excited at $514 \mathrm{~nm}$ and fluorescence was detected through the $560 \mathrm{~nm}$ longpass emission filter. Lucifer yellow was excited at $488 \mathrm{~nm}$, and fluorescence was detected between 510 and $530 \mathrm{~nm}$.

\section{Statistics}

Each experiment was repeated at least three times. Statistical comparisons were made by ANOVA (analysis of variance) followed by Fisher's PLSD test, using the program StatView (Abacus Concepts, Berkeley, CA, USA). Observations were considered significant if $P<0 \cdot 05$.

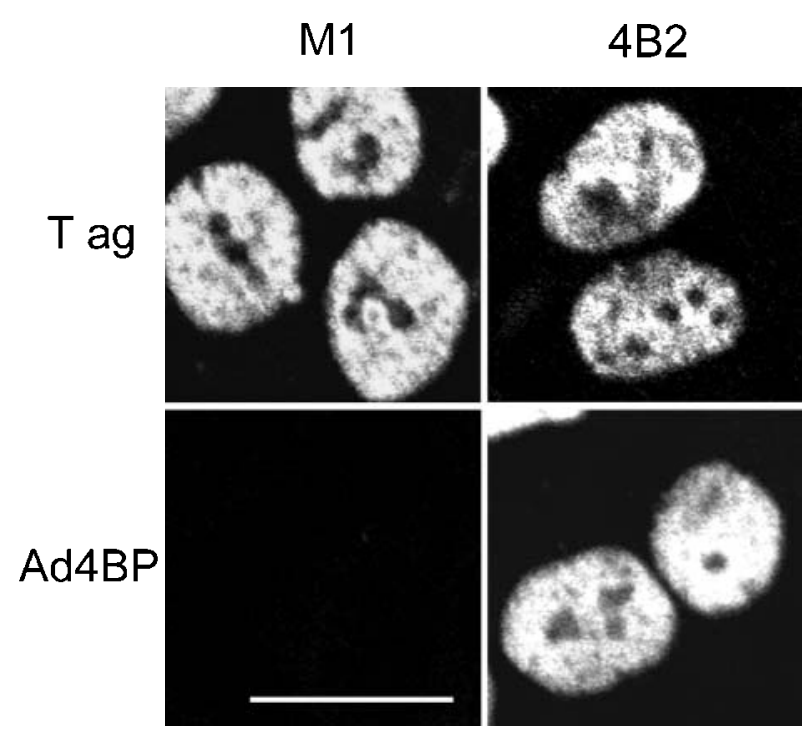

Figure 1 Immunocytochemical detection of SV40 large T antigen (Tag) and Ad4BP. Both SV40 large T antigen and Ad4BP were detected in the nuclei of 4B2 cells, and only SV40 large T antigen was detected in $\mathrm{M} 1$ cell nuclei. Bar: $10 \mu \mathrm{m}$.

\section{Results}

Establishment of a cell line with a highly steroidogenic property, $4 B 2$

Several highly steroidogenic clones were selected from 96 foci of mouse GC that were cotransfected with the genes encoding the SV40 large T antigen and Ad4BP. One of these clones, named 4B2, was then analyzed extensively. In addition, mouse primary GC were transfected only by the SV40 large T antigen, and one clone named M1 was used as control. Immunocytochemistry showed that 4B2 cells expressed both SV40 large T antigen and Ad4BP in their nuclei, whereas M1 cells expressed only SV40 large $\mathrm{T}$ antigen (Fig. 1). Although there is a slight possibility that the 4B2 cell line was not derived from GC, but rather from an ovarian fibroblast or a theca-interstitial cell, this seems unlikely, because expression of the inhibin alpha subunit was detected in the $4 \mathrm{~B} 2$ cells (Fig. 2). This is a special characteristic of GC (Hsueh et al. 1984). The amount of PRG secretion by $4 \mathrm{~B} 2$ cells was $77 \cdot 6\left(\mathrm{ng} / 10^{6}\right.$ cells/ $2 \mathrm{~h}$ ), which was 80 times higher than that produced by M1 cells (Fig. 3). To determine whether 4B2 cells retained the cAMP-signaling pathway responsible for PRG secretion, cells were treated with 8-Br-cAMP, cholera toxin (an activator of the stimulatory GTP-binding protein ( $G$ protein) and forskolin (an adenylate cyclase activator). Figure 3 shows that 4B2 cells increased their PRG secretion in a dose-dependent manner from 0.03 to $0.3 \mathrm{mM}$, reaching a maximum secretion rate of 470 (ng/10 cells per $2 \mathrm{~h}$ ), or about a sixfold increase over the basal level. PRG secretion was also stimulated by 


\section{goat $\lg G$}

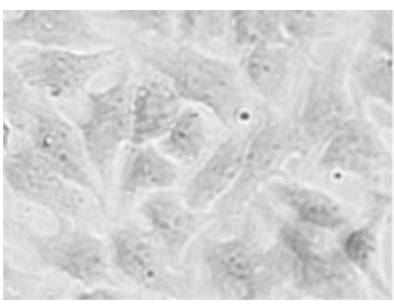

anti-inhibin alpha subunit antibody

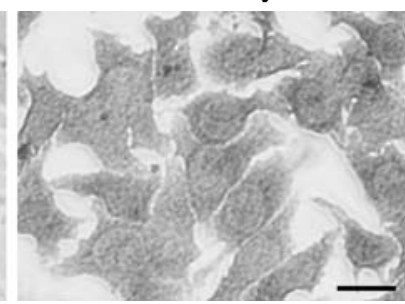

Figure 2 Immunocytochemical staining for inhibin alpha subunit in 4B2 cells. Cells were immunostained with goat immunogloblin G (IgG) or anti-inhibin alpha subunit antibody. Bar: $10 \mu \mathrm{m}$.

$200 \mathrm{ng} / \mathrm{ml}$ cholera toxin and by $10 \mu \mathrm{M}$ forskolin, but not by $100 \mathrm{ng} / \mathrm{ml} \mathrm{FSH}$ or $100 \mathrm{ng} / \mathrm{ml} \mathrm{LH}$ in the basic medium containing $10 \%$ FBS for $2 \mathrm{~h}$. These data indicate the existence of functional steroidogenic effectors that act downstream of the FSH and $\mathrm{LH}$ receptors in $4 \mathrm{~B} 2$ cells. We next determined whether this 8-Br-cAMP-responsive steroidogenesis requires protein synthesis, as is the case with primary cultured GC. Figure 4 shows that PRG accumulated in 4B2 cells over 16-h incubation, peaking at a concentration that was double the initial level. The accumulation reached a 50-fold increase over the initial level in the presence of $1 \mathrm{mM} 8-\mathrm{Br}$-cAMP. In contrast, this accumulation stimulated by 8 -Br-cAMP was greatly inhibited after $8-\mathrm{h}$ incubation by the presence of the protein synthesis inhibitor cycloheximide or after $16-\mathrm{h}$

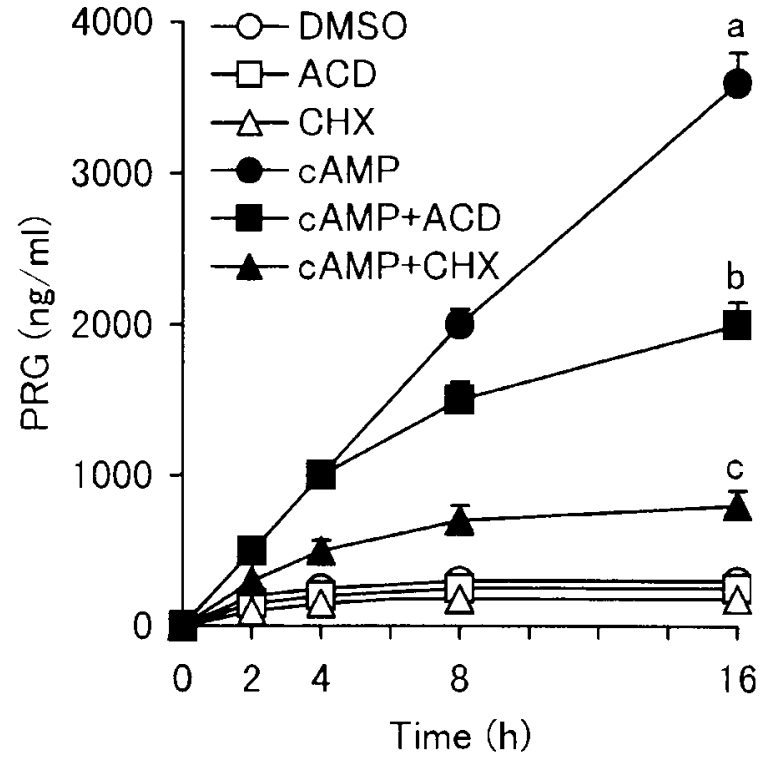

Figure 4 Effects of the protein synthesis inhibitor cycloheximide $(\mathrm{CHX})$ and the transcription inhibitor actinomycin D (ACD) on 8-Br-cAMP (CAMP)-stimulated progesterone (PRG) secretion in 4B2 cells. Cells were stimulated for $16 \mathrm{~h}$ by $1 \mathrm{mM} 8$-Br-cAMP with or without $1 \mu \mathrm{g} / \mathrm{ml} \mathrm{CHX}$ or $0 \cdot 1 \mu \mathrm{g} / \mathrm{ml} \mathrm{ACD}$. Values for 8-Br-cAMP-stimulated PRG secretion are different from those of control $(\mathrm{DMSO})$ at all the time points $(P<0 \cdot 01)$. $a$ is different from $b$ or $c(P<0 \cdot 05)$.

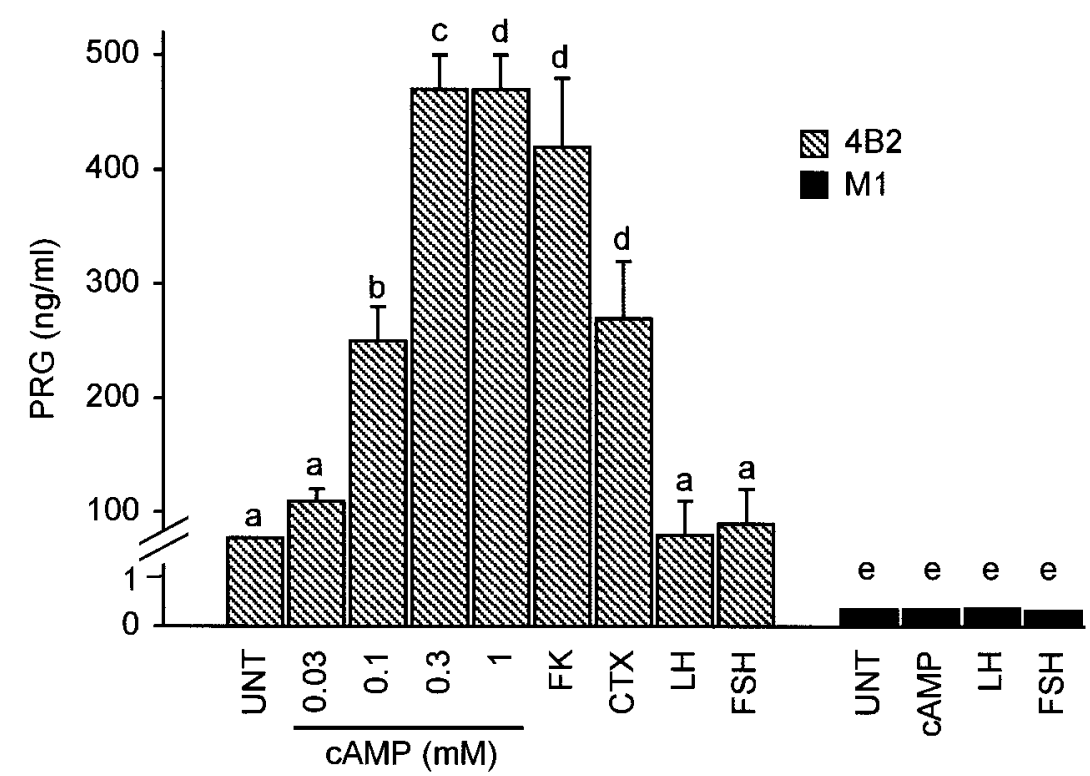

Figure 3 Steroidogenic capacity of 4B2 cells and M1 cells. Progesterone (PRG) was measured after cells were incubated in basic medium containing 10\% FBS for $2 \mathrm{~h}$, with or without 0.03-1 mM 8-Br-cAMP (cAMP), $200 \mathrm{ng} / \mathrm{ml}$ cholera toxin (CTX), $10 \mu \mathrm{M}$ forskolin $(\mathrm{FK}), 100 \mathrm{ng} / \mathrm{ml} \mathrm{FSH}$ or $100 \mathrm{ng} / \mathrm{ml} \mathrm{LH}$. $a$ is different from $b-d(P<0 \cdot 05) ; b$ is different from $C(P<0 \cdot 05)$; e is different from a-d $(P<0 \cdot 01)$. 


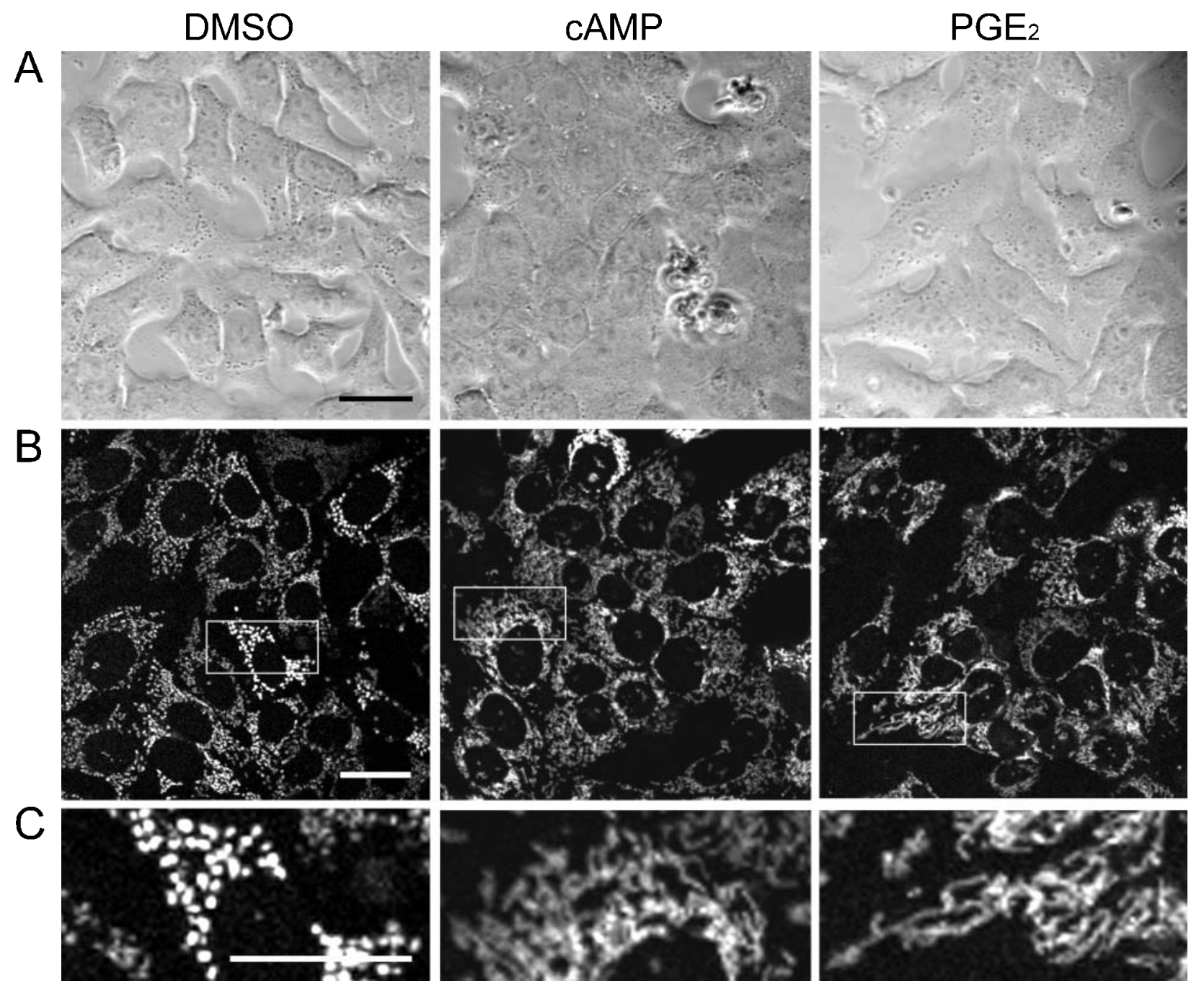

Figure 5 Effects of 8-Br-cAMP (cAMP) and $\mathrm{PGE}_{2}$ on cell shape and mitochondria morphology. Cells were treated with or without $0.3 \mathrm{mM}$ 8-Br-cAMP or $1 \mu \mathrm{g} / \mathrm{ml} \mathrm{PGE}_{2}$ in basic medium containing 5\% FBS for $48 \mathrm{~h}$. Phase-contrast micrographs of cells (A), fluorescent signals indicating mitochondria from MitoTracker Red (B). Enlarged areas of cells are indicated in each rectangle in panel B (C). The shape of 8-Br-cAMP-treated cells changed from a fibroblastic appearance to an epithelioid one, and their mitochondria changed from a dot-like to an elongated appearance, whereas in $\mathrm{PGE}_{2}$-treated cells, the cell shape did not change but the mitochondria were elongated. Bars: $10 \mu \mathrm{m}$.

incubation by the presence of transcription inhibitor actinomycin D, indicating that steroidogenesis depends on protein synthesis.

\section{Morphological changes were induced by 8-Br-cAMP}

In addition to the stimulation of steroidogenesis, activation of cAMP-mediated pathways in GC causes morphological differentiation in vivo and in vitro, including changes in cell shape, mitochondrial structure and gap junction formation. Mitochondrial elongation accompanied by extensive cristae formation is needed to meet the increased metabolic demands of steroidogenesis (Amsterdam et al. 1981).
Extensive formation of gap junctions is also essential for cooperative steroidogenesis of GC in developing antral follicles (Burghardt \& Matheson 1982). To determine whether 4B2 cells retain the ability to undergo such morphological alterations in response to $8-\mathrm{Br}-\mathrm{cAMP}$, cells were incubated for $48 \mathrm{~h}$ in the presence of $0.3 \mathrm{mM}$ 8-Br-cAMP. Figure 5A shows that 8-Br-cAMP induced a cell shape change from a fibroblastic appearance to an epithelioid one. Figure 5B and $\mathrm{C}$ show that mitochondria changed from a dot-like to an elongated appearance, consistent with the observed enhancement of PRG synthesis by 8 -Br-cAMP. The scrape-loading technique with Lucifer yellow was utilized for the determination of 


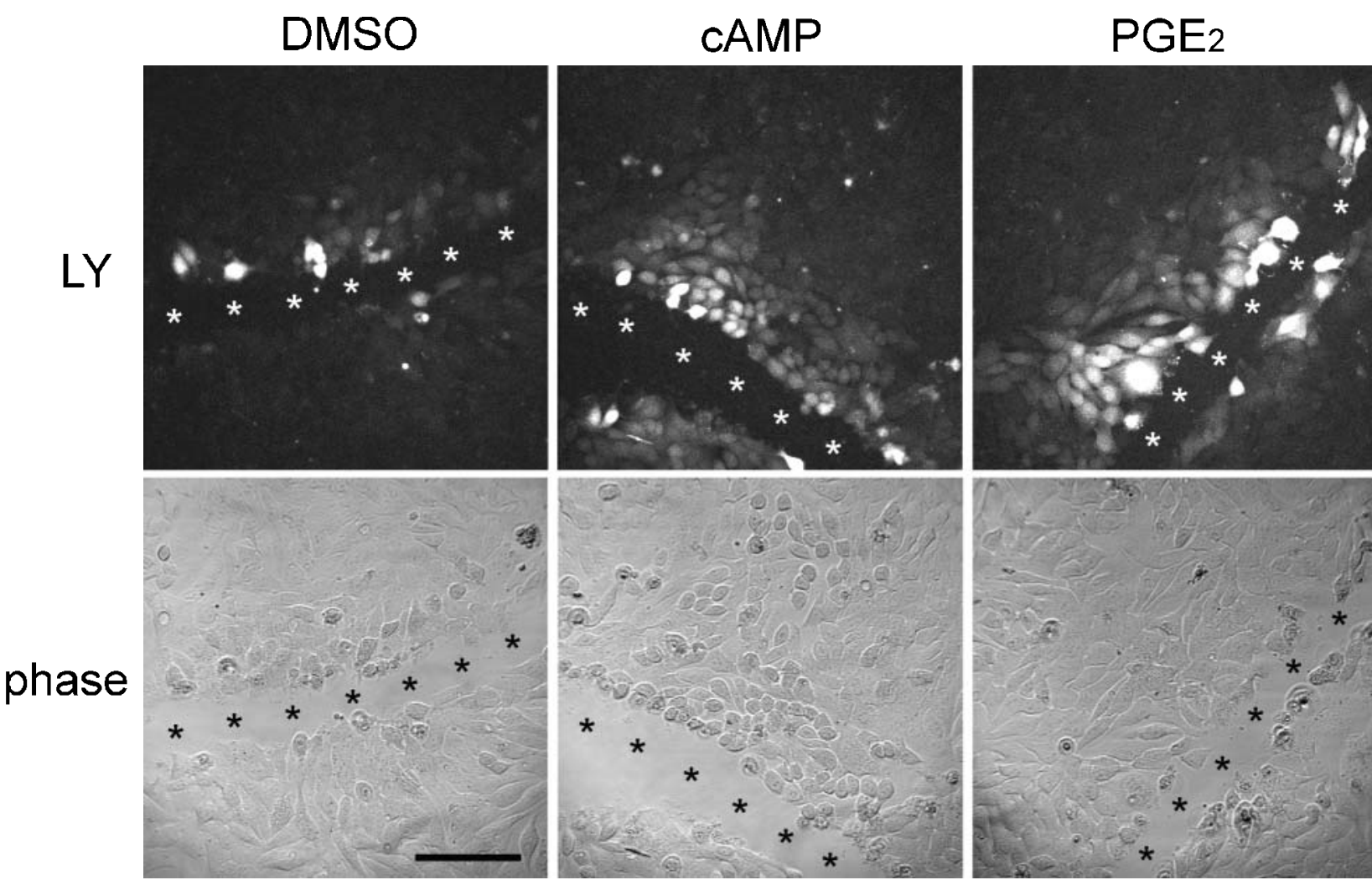

Figure 6 Induction of gap junction formation by 8-Br-cAMP (cAMP) and $\mathrm{PGE}_{2}$. Cells were treated with $0 \cdot 3 \mathrm{mM} 8-\mathrm{Br}-\mathrm{cAMP}$ or $1 \mu \mathrm{g} / \mathrm{ml}$ $\mathrm{PGE}_{2}$ in basic medium containing 5\% FBS for $24 \mathrm{~h}$. Subsequently, gap junction formation was evaluated by the Lucifer yellow scrape-loading technique. Fluorescent images of Lucifer yellow (LY) and phase-contrast micrographs of the same field (phase) after each treatment. A row of asterisks shows the cut field in a cell monolayer. Images represent three independent experiments. Bar: $30 \mu \mathrm{m}$.

gap junction formation. After cells were treated with $0.3 \mathrm{mM} 8$-Br-cAMP for $24 \mathrm{~h}$, a confluent monolayer was cut with a blade in the presence of the high-molecularweight dye Lucifer yellow. The damaged cells took up the dye, and some of it then diffused into undamaged neighboring cells through gap junctions. Similar to descriptions of differentiating primary cultured GC (Amsterdam et al. 1981), 4B2 cells incubated with 8-Br-cAMP showed a greater degree of dye diffusion than did control cells, confirming the 8-Br-cAMP-stimulated formation of gap junctions (Fig. 6). These data demonstrate that 4B2 cells retain the cAMP-dependent potential of morphological differentiation.

\section{Serum-stimulated cell proliferation was depressed by} 8-Br-cAMP

Cell growth of GC ceases while differentiation proceeds. To determine whether 4B2 cells display this property, 4B2 cells were cultured under the stimulation of $10 \%$ FBS in the presence or absence of $8-\mathrm{Br}-\mathrm{cAMP}$, and after $72 \mathrm{~h}$ the cell number was counted. FBS increased the cell number 17-fold in control cells, but only 4-fold in the presence of
0.3 mM 8-Br-cAMP (Fig. 7). This antiproliferative effect of 8-Br-cAMP was dose-dependent at concentrations ranging from 0.03 to $0.3 \mathrm{mM}$. These findings indicate that the growth of 4B2 cells may be interfered with by the cAMP signaling pathway.

\section{$P G E_{2}$ also induces differentiation properties}

Folliculogenesis, which is controlled by pituitary gonadotropins, is also regulated elaborately by a variety of intraovarian factors in an autocrine/paracrine way. $\mathrm{PGE}_{2}$ may be such a factor, as it is known to activate cAMP signaling and PRG synthesis in cultured GC (Kolena \& Channing 1972, McNatty et al. 1975). Cells were cultured overnight in the basic medium containing $0.2 \%$ FBS and thereafter were stimulated for $4 \mathrm{~h}$ with $1 \mu \mathrm{g} / \mathrm{ml} \mathrm{PGE}_{2}$. Cyclic AMP synthesis was stimulated by about 4-fold above control levels $(6800 \pm 873$ vs $1760 \pm 143 \mathrm{pmol} / \mathrm{dish}$, $n=3, P<0 \cdot 01)$. PRG secretion was $2 \cdot 7$-fold $(3 \cdot 7 \mathrm{ng} / \mathrm{ml}$ vs $1.3 \mathrm{ng} / \mathrm{ml}$ of control cells), and this level was similar to that of cells that were stimulated by $1 \mathrm{mM} \mathrm{8-Br-cAMP}$ under the same conditions. PRG secretion was mostly inhibited by $10 \mu \mathrm{M} \mathrm{H89}$, a PKA inhibitor (data not 


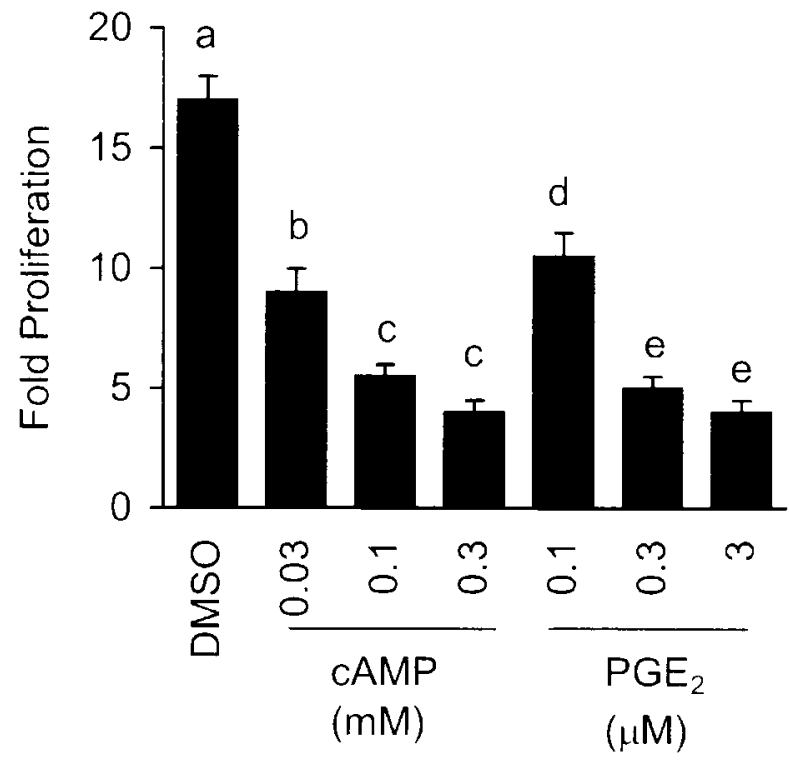

Figure 7 Effect of 8 -Br-cAMP and $\mathrm{PGE}_{2}$ on proliferation of $4 \mathrm{~B} 2$ cells. Cells were seeded at $1 \times 10^{4}$ cells $/ 3.5 \mathrm{~cm}$ plate and cultured for $72 \mathrm{~h}$ in basic medium containing $10 \% \mathrm{FBS}$ in the presence or absence of 8 -Br-cAMP $(0 \cdot 03,0 \cdot 1,0.3 \mathrm{mM})$ or $\mathrm{PGE}_{2}(0 \cdot 1,0 \cdot 3$, $3 \mu \mathrm{g} / \mathrm{ml}$ ). 8-Br-cAMP was added on days 0,1 and 2 , and $\mathrm{PGE}_{2}$ was added on days 0 and 2. Cells were then counted on day 3 . $a$ is different from $b$-e $(P<0.05) ; b$ is different from $c(P<0.05)$; $d$ is different from e $(P<0 \cdot 01)$.

shown), indicating that PKA is involved in $\mathrm{PGE}_{2}-$ stimulated PRG production. Moreover, we investigated whether $\mathrm{PGE}_{2}$ mimics the effects of 8-Br-cAMP on cell differentiation, as described in the above sections, with regard to cell and mitochondria structure, gap junction and cell proliferation (Figs 5-7). Cells were incubated in the presence of $5 \%$ FBS with or without $\mathrm{PGE}_{2}$ for $24 \mathrm{~h}$ (for studies of cell shape and mitochondria structure) or $48 \mathrm{~h}$ (for gap junction studies). Although this eicosanoid failed to induce a change in cell shape, it induced mitochondrial elongation and promoted gap junction formation, and both of these effects were comparable to those of $0.3 \mathrm{mM}$ 8-Br-cAMP treatment (Figs 5 and 6). $\mathrm{PGE}_{2}$ inhibited cell proliferation in a dose-dependent manner from 0.1 to $0 \cdot 3 \mu \mathrm{g} / \mathrm{ml}$ (Fig. 7). Collectively, these data indicate that $\mathrm{PGE}_{2}$, like 8-Br-cAMP, also induces differentiation properties, with the exception of cell conformation, in 4B2 cells.

\section{Discussion}

We have described a new cell line, 4B2, that has a cAMP-sensitive differentiation potential. This potential was obtained by transfecting the gene for Ad4BP together with the SV40 large $\mathrm{T}$ antigen gene into primary cultured mouse GC. Another cell line, M1, was obtained by transfection of the SV40 large T antigen gene, and it showed negligible steroidogenesis. Thus, the highly steroidogenic capacity of $4 \mathrm{~B} 2$ cells is apparently due to expression of the Ad4BP gene. Upon activation of cAMP signaling, the 4B2 cell line increases its steroidogenic capacity and undergoes changes in morphological features, and its cell growth is inhibited. These effects are similar to those seen in the differentiation process of primary cultured GC.

Although PRG secretion was responsive to the stimulatory $\mathrm{G}$ protein activator cholera toxin and to the adenylate cyclase activator forskolin, 4B2 cells did not respond to stimulation by FSH or LH. The molecular mechanisms underlying the loss of FSH and $\mathrm{LH}$ receptors upon immortalization of GC are not clear. It has been reported that the promoters for the FSH and $\mathrm{LH}$ receptors possess functional Ad4BP binding sites (Chen et al. 1999, Levallet et al. 2001). If $\mathrm{Ad} 4 \mathrm{BP}$ is truly a predominant regulator of the FSH and $\mathrm{LH}$ receptor genes, it might be expected that introduction of Ad4BP expression would result in expression of the FSH and $\mathrm{LH}$ receptors in $4 \mathrm{~B} 2$ cells, yet this was not the case. This implies that Ad4BP may not be a predominant regulator of the FSH and $\mathrm{LH}$ receptor genes. Alternatively, other regulatory factors in addition to Ad4BP may be required for expression of these receptors.

After 8-Br-cAMP stimulation, PRG secretion from 4B2 cells became evident within $2 \mathrm{~h}$ and thereafter increased linearly. In contrast, another report has shown that a GC line that was cotransfected with the SV40 large $\mathrm{T}$ antigen and Ha-ras oncogenes had a lag period of $12 \mathrm{~h}$ between 8-Br-cAMP stimulation and increased PRG production (Sun \& Amsterdam 1990). The acute PRG response of 4B2 cells to 8-Br-cAMP may not be surprising considering the important role of Ad4BP in steroidogenesis. Consistent with the ability of $\mathrm{PGE}_{2}$ to promote synthesis of cAMP, this eicosanoid also stimulated PRG secretion similarily to 8 -Br-cAMP stimulation.

Gap junctional communication has been reported to be enhanced and regulated by the cAMP-PKA pathway, in both in vivo and primary cultured GC (TenBroek et al. 2001). However, little information has been reported to date about gap junctional communication in GC lines. In extravillous trophoblast cells, transfection of the SV40 large $\mathrm{T}$ antigen DNA produces immortalization, but the mRNA levels of the gap junctional protein connexin 43 and gap junctional communication are both reduced (Khoo et al. 1998). If this result were applicable to GC, it would follow that 4B2 cells, because of their expression of SV40 large $T$ antigen, also might have a reduction in gap junctional communication. Nevertheless, we observed the cAMP-stimulated enhancement of gap junctional communication in 4B2 cells. This suggests the existence of the counteractive effect, which is probably indirect, of Ad4BP against the effect of SV40 large T antigen.

It has been reported for other cell types that activated PKA phosphorylates actin-associated proteins, thus 
regulating the cytoskeleton and leading to cell movement (Prat et al. 1993, Lambrechts et al. 2000). The cell shape change of $4 \mathrm{~B} 2$ cells in response to $8-\mathrm{Br}-\mathrm{cAMP}$ may be accounted for by the activation of PKA. Nevertheless, despite its ability to affect cAMP synthesis, $\mathrm{PGE}_{2}$ did not cause changes in cell conformation in 4B2 cells. Although the reason for this is not clear, one explanation may be that $\mathrm{PGE}_{2}$ activates an additional signaling pathway that reverses a cAMP-mediated cell shape change. For example, phosphatidylinositol-3 kinase is known to be activated by $\mathrm{PGE}_{2}$ (Fujino et al. 2003) and to function in actin regulation (Papakonstanti \& Staurnaras 2002). In contrast with their distinct effects on cell shape change, both 8-Br-cAMP and $\mathrm{PGE}_{2}$ induced mitochondria elongation, which is an alteration linked to increased steroidogenesis. These differential effects on cell shape and mitochondria structure suggest that the cell shape change, which has been assumed to be associated with increased steroidogenesis during GC differentiation (Hsueh et al. 1984), may in fact be dispensable for steroidogenesis.

Cell growth of 4B2 cells stimulated by FBS was inhibited by 8 -Br-cAMP and $\mathrm{PGE}_{2}$, as has also been observed in GC both in vivo and in vitro (Hsueh et al. 1984). This inverse relationship between differentiation and cell growth might be linked to the overexpression of Ad4BP in 4B2 cells. In agreement with this hypothesis, FSH and 8-Br-cAMP have been reported to increase Ad4BP mRNA levels, leading to aromatase expression, and to prevent mitogen-stimulated mitosis, whereas treatment with Ad4BP antisense oligonucleotides reverses these effects (Shapiro et al. 1996). It is unclear how the transcription factor transmits the cAMP signal to the mitotic pathway resulting in growth inhibition in GC. There have been hints in a previous report that $\mathrm{MyoD}$, a transcription factor that differentiates muscle cells, also induces growth arrest through stimulation of p21 expression (Halevy et al. 1995). By analogy, it is conceivable that p21 expression associated with cell growth may be under the regulation of Ad4BP.

When primary GC are cultured, serum-free conditions, free from growth factors, are obligatory for the in vitro induction of cell differentiation (Shapiro et al. 1996). In contrast, 4B2 cells can differentiate functionally and morphologically even in the presence of serum. This may reflect the case of GC found in vivo in antral follicles, which differentiate in follicular fluid containing numerous serum growth factors (Morohashi et al. 1993). One of the authors of this study reported that even nonsteroidogenic cells can activate the promoter of a steroidogenic P-450 gene after transfection of the Ad4BP gene, if the cells possess the protein kinase A system. Thus, our purpose is not only to understand the acquisition of steroidogenic capacity conferred by Ad4BP gene expression, but also to determine whether enforced expression of the Ad4BP gene results in recovery of differentiation characteristics other than steroidogenesis, such as morphological differ- entiation and cell growth. It is known that these characteristics are lost after the expression of an oncogene, in this case SV40 large T antigen, in primary cultured cells. The present results obtained with 4B2 cells clearly indicate that activation of the cAMP pathway, which probably leads to PKA activation, induces morphological changes, including mitochondrial elongation, gap junction formation and growth inhibition. Notably, the experiments utilizing 8-Br-cAMP and $\mathrm{PGE}_{2}$ provide clear evidence that the cell shape change during differentiation may be independent of increased steroidogenesis. To our knowledge, $4 \mathrm{~B} 2$ is the first line of GC that constitutively express the Ad4BP gene and that undergo functional and morphological differentiation upon activation of cAMP signaling. This cell line may be useful for future studies of GC involving Ad4BP during folliculogenesis in the ovary.

\section{Acknowledgement}

We thank Dr T Takizawa for his continuous encouragement. The authors declare that there is no conflict of interest that would prejudice the impartiality of this scientific work.

\section{References}

Amsterdam A, Knecht M \& Catt KJ 1981 Hormonal regulation of cytodifferentiation and intercellular communication in cultured granulosa cells. PNAS 78 3000-3004.

Amsterdam A, Zauberman A, Meir O, Pinhasi-Kimhi B, Suh BS \& Oren M 1988 Cotransfection of granulosa cells with simian virus 40 and Ha-RAS oncogene generates stable lines capable of induced steroidogenesis. PNAS $857582-7586$.

Asakai R, Akita Y, Tamura K, Kenmotsu N \& Aoyama Y 1995 Protein kinase $\mathrm{C}$-dependent down-regulation of basic fibroblast growth factor (FGF-2) receptor by phorbol ester and epidermal growth factor in porcine granulosa cells. Endocrinology 136 3470-3479

Burghardt RC \& Matheson RL 1982 Gap junction amplification in rat ovarian granulosa cells. Developmental Biology 94 206-215.

Chen S, Shi H, Liu X \& Segaloff DL 1999 Multiple elements and protein factors coordinate the basal and cyclic adenosine $3^{\prime}, 5^{\prime}$-monophosphate-induced transcription of the lutropin receptor gene in rat granulosa cells. Endocrinology 140 2100-2109.

Fujino H, Xu W \& Regan JW 2003 Prostaglandin $\mathrm{E}_{2}$ induced functional expression of early growth response factor-1 by EP4, but not EP2, prostanoid receptors via the phosphatidylinositol 3-kinase and extracellular signal-regulated kinases. Journal of Biological Chemistry 278 12151-12156.

Gilman AG 1970 A protein binding assay for adenosine $3^{\prime}, 5^{\prime}$-cyclic monophosphate. PNAS 67 305-312.

Halevy O, Novitch BG, Spicer DB, Skapek SX, Rhee J, Hannon GJ, Beach D \& Lassar AB 1995 Correlation of terminal cell cycle arrest of skeletal muscle with induction of p21 by MyoD. Science 267 1018-1021.

Hosokawa K, Dantes A, Schere-Levy C, Barash A, Yoshida Y, Kotuji F, Vlodavsky I \& Amsterdam A 1998 Induction of Ad4BP/SF-1, steroidogenic acute regulatory protein, and cytochrome P450 scc enzyme system expression in newly established human granulosa cell lines. Endocrinology 139 4679-4687. 
Hsueh AJW, Adashi EY, Jones PBC \& Welsh TH 1984 Hormonal regulation of the differentiation of cultured granulosa cells. Endocrine Review 5 76-127.

Keren-Tal I, Dantes A, Plehn-Dujowich D \& Amsterdam A 1997 Association of Ad4BP/SF-1 transcription factor with steroidogenic activity in oncogene-transformed granulosa cells. Molecular and Cellular Endocrinology 127 49-57.

Khoo NKS, Zang Y, Bechberger JF, Bond SL, Hum K \& Lala PK 1998 SV40 Tag transformation of the normal invasive trophoblast results in a premalignant phenotype. II. Changes in gap junctional intercellular communication. International Journal of Cancer $\mathbf{7 7}$ 440-448.

Kim DW, Uetsuki T, Kaziro Y, Yamaguchi N \& Sugano S 1990 Use of the human elongation factor $1 \alpha$ promoter as a versatile and efficient expression system. Gene 91 217-223.

Kolena J \& Channing CP 1972 Stimulatory effects of LH, FSH, and prostaglandins upon cyclic $3^{\prime}, 5^{\prime}$-AMP levels in porcine granulosa cells. Endocrinology $901543-1550$.

Lala DS, Rice DA \& Parker KL 1992 Steroidogenic factor 1, a key regulator of steroidogenic enzyme expression, is the mouse homolog of fushi tarazu factor 1. Molecular Endocrinology 6 1249-1258.

Lambrechts A, Kwiatkowski AV, Lanier LM, Bear JE, Vandkerckhove J, Ampe C \& Gertler FB 2000 cAMP-dependent protein kinase phosphorylation of EVL, a Mena/VASP relative, regulates its interaction with actin and SH3 domains. Journal of Biological Chemistry 275 36143-36151.

Levallet J, Koskimies P, Rahman N \& Huhtaniemi I 2001 The promoter of murine follicle-stimulating hormone receptor: functional characterization and regulation by transcription factor steroidogenic factor 1. Molecular Endocrinology 15 80-92.

Luo C, MacPhail SH, Dougherty GJ, Naus CC \& Olive PL 1997 Radiation response of connexin 43-transfected cells in relation to the 'contact effect'. Experimental Cell Research 234 225-232.

McNatty KP, Henderson KM \& Sawers RS 1975 Effects of prostaglandin $\mathrm{F}_{2 \alpha}$ and $\mathrm{E}_{2}$ on the production of progesterone by human granulosa cells in tissue culture. Journal of Endocrinology 67 $231-240$

Morohashi K, Zanger UM, Honda SI, Hara M, Waterman MR \& Omura T 1993 Activation of CYP11A and CYP11B gene promotes by the steroidogenic cell-specific transcription factor, Ad4BP. Molecular Endocrinology 7 1196-1204.

Nuclear Receptor Nomenclature Committee 1999 A unified nomenclature system for the nuclear receptor superfamily. Cell $\mathbf{9 7}$ 161-163.

Papakonstanti EA \& Staurnaras C 2002 Association of PI-3 kinase with PKA1 leads to actin phosphorylation and cytoskeletal reorganization. Molecular Biology of the Cell 13 2946-2962.

Prat AG, Bertorello AM, Ausello D \& Cantiello HF 1993 Activation of epithelial $\mathrm{Na}^{+}$channels by protein kinase A requires actin filaments. Journal of Physiology 265 C224-233.

Shapiro DB, Pappalardo A, White BA \& Peluso JJ 1996 Steroidogenic factor-1 as a positive regulator of rat granulosa cell differentiation and a negative regulator of mitosis. Endocrinology 137 1187-1195.

Sun BS \& Amsterdam A 1990 Establishment of highly steroidogenic granulosa cell lines by cotransfection with SV40 and Ha-ras oncogene: induction of steroidogenesis by cyclic adenosine $3^{\prime}-5^{\prime}$-monophosphate and its suppression by phorbol ester. Endocrinology 127 2489-2500.

TenBroek EM, Lampe PD, Solan JL, Reynhout JK \& Johnson RG 2001 Ser364 of connexin43 and the upregulation of gap junction assembly by cAMP. Journal of Cell Biology 155 1307-1318.

Zhao L, Bakke M, Krimkevich Y, Cushman LJ, Parlow AF, Camper SA \& Parker KL 2001 Steroidogenic factor 1 (SF-1) is essential for pituitary gonadotrope function. Development 128 147-154.

Received 22 December 2004

Accepted 6 January 2005

Made available online as an

Accepted Preprint 12 January 2005 